\title{
Leadership Skills - Empirical Evidence from Third-Line Leaders in the Kuwait Oil and Gas Sector
}

\begin{abstract}
Leadership has been widely studied yet there is much to be explored as it differs based on the context. The Kuwait oil and gas sector is strongly associated with the growth of the economy. The role of the first-line leaders in the Kuwait oil and gas sector reflects the performance of the organization. The study critically analyses and presents the 'needs', 'skills' and 'capabilities' development of third-line leaders working in the Kuwait's Oil and Gas Sector companies.

The empirical data is collected through in-depth semi-structured interviews from 42 third-line leaders. The findings point to the importance of business knowledge, technical skills, leadership skills, communication skills, decision-making skills, and change management skills as factors that contribute to leadership development and skills.
\end{abstract}

Alawi Taqi Gas.

Index Terms - Development, Kuwait, Leadership, Oil and

\section{INTRODUCTION}

The Oil and Gas Sector is a very complex and highly technical field that it is essential to have technical competencies. Furthermore, there could be catastrophic failures if technical errors are made.

The development of third-line leadership skills and capabilities provides an added opportunity for contribution to knowledge in the field of leadership. Furthermore, it is fundamentally important that with the advent of the Kuwaitisation (localisation) policy adopted by the government of Kuwait and as the existing leaders are succeeded by a new generation of leaders, their needs must be clearly understood from their own perspectives (a social constructivist perspective), and subsequently the development of such skills and competencies is necessary to ensure continuity and realisation of organisational objectives.

In addition, the emerging business environment now requires a new set of leadership skills that are aligned to the requirements of the future (O'Brien and Robertson, 2009). The dynamics and complexity of the Oil and Gas Sector places enormous demands on the management and leadership competencies at all organisational levels, but of particular importance to this study is the third level of leadership. A more comprehensive theoretical framework is therefore required to understand the processes and interactions underlying leadership needs and skills and the development thereof at this leadership level.

Alawi Taqi, Kuwait

\section{PROBLEM STATEMENT}

It was noted that in view of the complex nature of the Oil and Gas Sector, there was a need to acquire the latest skills considered to be lacking.

Effectiveness at task-oriented behaviours hinges on the ability to clarify task requirements and structure tasks around an organization's mission and objectives [2]. As the plans are implemented, it is important that first they are well communicated, and that there is a buy-in from subordinates. The duties and responsibilities of subordinates must be clearly denoted, with individual targets set and agreed with subordinates. Within the oil sector in Kuwait, part of the problem is that there is over-staffing, and roles tend to overlap and are ill-defined, sometimes creating confusion and lack of accountability and responsibility.

This aspect of the work ensures that the work is done accordingly, and where possible corrective action is taken. It requires gathering information about the operation's unit, having progress review meetings, taking corrective action where possible. Tools such as the Balance Score Card are being employed to facilitate this process and assess how well an organisation is achieving its objectives. However, within the Kuwaiti oil sector, a lack of discipline and the inability of managers to take disciplinary action hinders organisational performance.

As far as leadership development from a Western cultural perspective is concerned, the main barriers in Kuwait appear to be that tribal and familial interdependence remains deeply rooted, and this extends into both public and private organisations (indeed, the public-private distinction is of little utility in countries where governance and big business are pervaded by tribal oligarchies). The classical management preoccupation with efficiency remains compromised by traditional attitudes that place kin and tribal allegiances above all else. Leaders might be effective at task-, relations- and change-oriented leadership behaviours, or they might be effective at only one or two, or perhaps none [3]. Such variation in leadership behaviours has implications for leadership effectiveness.

\section{RESEARCH OBJECTIVES}

Very little is understood about the applicability of the concept of leadership in the Arab World in general, and the GCC states such as Kuwait in particular. Potential inadequacies of Western models have been highlighted in the 
past when being applied to non-Western countries [4]. In short, to better target applicable leadership skills to the Arab region and achieve cultural congruence that can yield increased usefulness, Arab understandings of the topic must be fully incorporated [5]-[7].

The objective of this study is to understand the leadership skills of third line leaders in the Kuwait oil and gas sector. Empirical evidence from the third line leaders are collected and the findings are presented in this paper.

\section{METHODOLOGY}

Interpretivist/constructivist approaches to research have the intention of understanding "the world of human experience" [8], suggesting that "reality is socially constructed" [9]. It is argued that the interpretivist/constructivist researcher tends to rely upon the "participants' views of the situation being studied" [10] and recognises the impact on the research of their own background and experiences. Authors (for example, [10] and [11] claim that interpretivist researchers discover reality through participant's views, their own background and experiences.

The research has collected data from third-line leaders in the Kuwait Oil and Gas sector. Each of them was identified and approached with the research intentions and the need to collect data from them. There are 42 third-line leaders and data were collected from each of them through personal in-depth interviews. This was a semi-structured interview, and each of the interviews were carried out in the participant respective offices. Voice recorders was used with prior permission of the participants and after the interviews were completed, the data was transcribed, coded and discussed.

The researcher has been working in the oil and gas sector and therefore know several of the third-line leaders and managers. Based on this an open relationship between the researcher and the respondents was established. This helped in the respondents speaking freely about their current work scenario and answering the questions to the best of their ability.

\section{KUWAIT}

This paper addresses the notion of leadership in Muslim countries and seeks to understand issues pertaining to leaders and leadership within an Islamic country, Kuwait. Kuwait is a predominantly Islamic country, consisting of about $65 \%$ Sunnis and 35\% Shi'ite Muslims. There is freedom for other religions for as long as they accept the pre-eminence of Islamic religion in public affairs. As a result of these divisions, the concept of leaders and leadership has evolved across the centuries and has been largely influenced by the nature of power structure and sectarian allegiances [12]. However, they both have a practical ideology (Islam) that tries to focus on equity among people, hard work, and the belief in one god, Allah. The internalization of Islamic concepts strengthens certain qualities such as honesty, trust, solidarity, loyalty and tolerance [13].

Kuwait is a developing country that has been experiencing rapid modernization and westernization based on exploitation of the world's fifth largest oil reserves. Kuwait Petroleum Corporation (KPC), established in 1980, encompasses all aspects of the oil industry. As a fully state-owned public entity owned by the government of Kuwait, it brings together all other state-owned elements of the Kuwaiti Oil and Gas Sector under one corporate umbrella. KPC's total assets are more than 17 billion Kuwaiti Dinars ( $\$ 59$ billion). KPC is a major contributor to the country's revenues and it is estimated that the revenues from oil comprise about half of the country's GDP [14]. KPC owns ten subsidiaries inside and outside Kuwait.

Favourable oil prices and increased demands in oil made the country wealthy with a stable economy. But during the recent years the oil prices has fallen sharply and thus hitting the economy as the country depended heavily on its oil production and exports. Prior to the oil price drop itself Kuwait had a 2020 strategy which focuses on the following:

- Developing production capacity

- Maximizing reserves growth

- Maximizing gas exploration and production

- Health, safety and environmental commitment

- Develop research and technology

- Enhance corporate culture and image

- Enhance support services

The current and the anticipated increase in drilling and exploration activities will require more operations such as drilling, wire-line logging, well completions and other related oil field activities. These activities in turn will require more highly skilled manpower and equipment by the upstream oil service companies, thereby justifying the need to develop leaders' capabilities, which is the subject of this research. It is the third line leaders have the responsibility of ensuring that these strategies and objectives that are set by the management are achieve through their skills and interaction with the team.

\section{FINDINGS AND DISCUSSIONS}

The sampled companies are the most major firms in Kuwait (in view of the country's dependence on oil); to that end, top management has been trying to develop the needs of their employees through various initiatives, one of which was the initiation of the personal development program four years ago. Whilst some of the respondents felt that they possessed the requisite leadership and managerial skills required for their jobs, others felt otherwise, and even thought that top management were not aware of their needs. They felt that although the personal development program existed, it was outdated and that there was a need to determine the specific needs of junior leaders in view of the fast-changing technology within the Oil and Gas Sector. It was therefore important to investigate the skills and capabilities that these junior leaders or Team Leaders required to perform their duties. 


\section{A. Business Knowledge}

It was important to establish from these Team Leaders how much knowledge of the business they had and why possession of such knowledge of the business was important when running the companies.

The majority of these respondents therefore had general knowledge of the Oil and Gas Sector. They generally agreed that both leadership and managerial experience was important when occupying the position of a Team Leader. They mentioned that possession of both technical and administrative knowledge was important to be able to make effective decisions. Therefore, the immediate need required was possession of technical and administrative knowledge for these Team Leaders.

\section{B. Technical Skills}

The roles and responsibilities of Team Leaders require that they possess strong technical skills, as in the majority of cases they were heading technical units. Literally all the respondents highlighted the need for them to have technical skills, although in some cases such technical skills were lacking. The Kuwaitisation policy would appear to instigate appointment and promotion based on academic qualifications rather than experience, reflecting a shallow and limited concept of education and training on the part of the government (e.g. no notion of internships, apprenticeships, etc.)

Technical skills were identified as a requisite primarily because of the complex nature of the work in the Oil and Gas Sector. However, it was also highlighted that such technical skills were lacking in the majority of cases, partly because the function had been outsourced, and partly because many of the Team Leaders had been quickly been promoted to these positions because of the Kuwaitisation policy, and not enough transfer of knowledge had taken place between the more experienced personnel and the recently promoted Team Leaders.

\section{Leadership Skills}

Leadership and managerial skills were considered to be very important, as this was a junior leadership position. Managerial and leadership skills were considered to be very important and needed to be developed. This was considered essential in view of the fact that a Team Leader position was a junior leadership position and it required that the incumbent possess such skills. This was a view generally supported by most of the respondents.

Leadership in this case can be understood to imply the collective action, orchestrated in such a way as to bring about significant change while raising the competencies and motivation of all those involved. These leadership skills encompass the capacity to be a catalyst for strategic and cultural change, to achieve results; to empower others; leading planning teams and carrying out and improving value added work; supporting function and system and to exhibit a capacity to take initiation and influence others. Many of these Team Leaders are expected to fill the roles of leading processes, e.g. coordinating with upper management, leading the team in goal setting processes, providing overall leadership for the team, supporting team members in operations, planning and site processes.

Research shows that the management and leadership of people has a greater effect on productivity and profitability than the combined effects of strategy, quality, technology, and research and development [15]. Effective performance is derived from coordinated and synchronised actions of multiple individuals who share responsibility for team outcomes especially in such large organisations such as those in the Oil and Gas Sector.

\section{Communication Skills}

Communication skills were identified as another important theme, and this was more so the case in a society where communication tends to be top-down. It was highlighted that leaders ought to listen to the views of lower level employees and generally improve the communication within and across the organisations. It was important that the Team Leaders attentively listen to the needs of their subordinates and such skills were considered to be lacking.

The participants stated that communication is important, especially when it comes to cascading the organisation's strategy downwards. This is important because in such organisations the Team Leaders and the lower-level employees might not be involved in the strategy formulation process.

Communication skills were considered to be very important for Team Leaders and leaders in general. There was a need to communicate not just top-down, as is the current practice, but to also bottom-up and laterally. It was important that communication skills be generally improved within all the companies, especially if the strategies were to be well understood and implemented properly.

Communication is the ability to present ideas through written and oral means and thereby maximizing understanding of the message by the audience. Communication skills within this context entailed active listening and appropriate and skilful use of language and use of body language. Kuwaitis by their very nature talk a lot amongst themselves as part of their socialisation. Whilst such communication may be considered as lateral, at the workplaces it was noted that possibly because Kuwait may be considered as a class society with people classified in different social strata, communication between top management and lower level employees and in particular with Team Leaders tended to be top-down. Such communication mechanisms did not lead to free flow of information amongst organisational members.

Leaders use formal and informal information flows to get the message out, to stay current, to learn about problems, and 
to shape the conduct of work and the way decisions are made. Informal information flows represent critical and often misunderstood processes whereby knowledge circumvents the formal processes because of sensitivity issues. The method of providing feedback (over time, indirectly versus in one long session) and the style of communicating constructive criticism (indirect and polite versus direct and frank) was an important consideration. To avoid maintaining the status quo and paint a picture of the desired new state for followers, leaders must communicate the need for change. Other organisational members need to understand why behaviours and routines need to change [16]-[17].

\section{E. Decision-making Skills}

Another skill identified was the need for these Team Leaders to make informed decisions based ideally on proper analysis and justification. The findings showed that in majority of situations quick decision-making capability is required, but such skills were missing with most of the third-line leaders.

It was noted that Team Leaders required decision-making skills more so that their roles and responsibilities entailed making key decisions pertaining to their work and that of their subordinates.

Decision flows represent both the formal and informal sequence an organisation follows in making decisions. These include both vertical and horizontal sequences, specifically between management and operational levels and between and within departments. Knowing how decision flows work helps leaders leverage the flows to achieve their goals and to make changes to the decision flows that can help in achieving these goals. Information flows are critical in support of the decision-making flows and work flows because information provides the critical knowledge about internal and external factors that affect the organisation's management flows and how these flows respond to these factors.

\section{F. Change Management Skills}

Change is a driving force of leadership and management development. Change management skills within the Kuwait Oil and Gas Sector meant developing an organisational culture that embraces continuous learning and building support mechanisms to create and sustain change efforts, managing the change process, and encouraging individual as well as structural change in the organisation and dealing with complexities. Therefore, improving the adaptation skills of these third-line leaders is critical in helping them respond to new circumstances imposed from external factors outside of the direct control of the organisation.

Change management was considered to be an important leadership skill that was missing amongst the third-line leaders. Leaders must be adaptable to changing and challenging circumstances. A rigid one-way only approach leads to failure for the individual and the organisation. The personality of the leader is critical.
Most authorities agree that the main task of leaders is to bring about change and the importance of leadership is to bring about change [18]. However, it is important to note that much is said about how best to bring about such critical leadership skills. This is one of the reasons why [19] philosophy draws out the pressing need for change projects to be led by managers who have the necessary attributes to be able to implement them. The author [19] also recognises that leadership and change management are inextricably linked.

There is a need to pay attention to the potentially beneficial linkage between leadership development and organisational change [18]. This is more so in the case of the Kuwait's Gas and Oil Sector, where change management projects have not been implemented successfully, possibly because these leaders lacked the requisite leadership skills and competencies. It is also important to note that one of the practical rationales for undertaking this study is Kuwait's inability to implement Oil and Gas Sector projects. It was for such reasons that it was important for these Team Leaders to identify their needs and map these against leadership development needs.

The Oil and Gas Sector, like most industries in the GCC, is undergoing a profound transition brought about by numerous factors, including technology, government policies, economic diversification and the globalization of the economy. The changing business landscapes require a different set of leadership skills at this leadership level in order for them to be effective.

\section{RECOMMENDATIONS}

Managers need to have managers/leaders who have the necessary attributes to be able to implement them. However, preliminary results suggest that these emerging organisational leaders are significantly under-prepared for the challenges that lie ahead, partly because they have been fast accelerated and assumed positions of responsibility without necessarily having been well cultivated with the necessary leadership competencies.

\section{REFERENCES}

[1] E. O'Brien and P. Robertson. "Future leadership competencies: from foresight to current practice," J. Euro. Ind. Tra. vol. 3, 2009, pp. 371-380.

[2] G. W. Goussak, J. K. Webber, and E. Ser. "Applying the Full Range Leadership Model to Managing Employees in the Las Vegas Casino-Gaming Industry," J. Gamb. Bus. Eco., vol. 5, 2011, pp. 47-67.

[3] G. Yukl. Leadership in Organizations. Eight Edition. Upper Saddle River, N.J: Pearson Education. 2013.

[4] P. B. Smith, M. Achoui, and C. Harb. "Unity and diversity in Arab managerial styles," Int. J. Cross Cult. Manag. vol. 7, 2006, pp. 275-289.

[5] G. H. Hofstede, Culture's Consequences: International differences in work-related values, London: Sage Publications. 1980.

[6] G. Hofstede, Culture's Consequences: International differences in work related values. Sage: London. 1984

[7] R. J. House, and M. Javidan, Overview of GLOBE, Culture, leadership, and organizations: The GLOBE study of 62 countries. In R. J. House, P. J. Hanges, M. Javidan, P. W. Dorfman, and V. Gupta, Ed. Thousands Oak, CA: Sage Publications. 2004. pp. 9-28. 
[8] L. Cohen, and L. Manion, Research methods in education (4th ed.). London: Routledge. 1994.

[9] D. M. Mertens, Research and Evaluation in Education and Psychology: Integrating Diversity with Quantitative, Qualitative, and Mixed Methods, Thousand Oaks, CA: Sage Publications. 2005.

[10] J. Creswell, Research design: Qualitative, quantitative and mixed methods approaches. Thousand Oaks: Sage Publications. 2003.

[11] D. Yanow, and P. Schwartz-Shea. Interpretive Approaches to Research Design: Concepts and Processes. Netherlands: Routledge. 2011

[12] A. J. Ali, "Islamic perspectives on leadership: a model," Int J Islam Middle E Finance Manag, vol. 2, 2009, pp. 160-180.

[13] C. J. Rees and R. Althakhri, "Organizational change strategies in the Arab region: A review of critical factors". J. Bus. Eco. Manag. vol. 9 , 2008, pp. 123-132.

[14] CIA.gov (2019, November), World Factbook - Kuwait. Available: https://www.cia.gov/library/publications/the-world-factbook/geos/ku.h tml

[15] P. Zeus and S. Skiffington, Coaching at Work, McGraw-Hill, Sydney. 2001.

[16] C. M. Fiol, D. Harris, and R. House, (1999). "Charismatic leadership: Strategies for effecting social change", Lead. Q., vol. 10, 1999. pp. 449-482.

[17] J. Kotter, "Leading change: Why transformation efforts fail," Harv. Bus. Rev. vol. 73, 1995, pp. 59-67.

[18] B. Burnes, "Developing Change and Leadership Capabilities", Stra. Dir. vol. 20, 2004, pp. 24-26.

[19] J. P. Kotter, Leading change. Cambridge, MA: Harvard Business School Press. 1996.

\section{Alawi Taqi.}

Worked at the commercial Departments in Kuwait Oil \& Gas sector for 19 years and now heading as the CEO of a holding company with diversified businesses.

MBA from the Maastricht Business School and PhD from Stirling University Scotland. Faculty member (Lecturer) at the American University of Kuwait 2011-2012 (teaching Management, Strategic Management, Leadership \& Corporate Decision Making). Former Advisory Board member at the Business College at American University of Kuwait. former British Business Forum member at the British Embassy - Kuwait. 